\title{
A method for analysis of vanillic acid in polar ice cores
}

\author{
M. M. Grieman ${ }^{1}$, J. Greaves ${ }^{2}$, and E. S. Saltzman ${ }^{1}$ \\ ${ }^{1}$ Department of Earth System Science, University of California, Irvine, USA \\ ${ }^{2}$ Department of Chemistry, University of California, Irvine, USA \\ Correspondence to: M. M. Grieman (mgrieman@uci.edu) \\ Received: 20 May 2014 - Published in Clim. Past Discuss.: 4 July 2014 \\ Revised: 9 November 2014 - Accepted: 6 January 2015 - Published: 11 February 2015
}

\begin{abstract}
Biomass burning generates a wide range of organic compounds that are transported via aerosols to the polar ice sheets. Vanillic acid is a product of conifer lignin combustion, which has previously been observed in laboratory and ambient biomass burning aerosols. In this study a method was developed for analysis of vanillic acid in melted polar ice core samples. Vanillic acid was chromatographically separated using reversed-phase liquid chromatography (HPLC) and detected using electrospray ionization-triple quadrupole mass spectrometry (ESI-MS/MS). Using a $100 \mu \mathrm{L}$ injection loop and analysis time of $4 \mathrm{~min}$, we obtained a detection limit of $77 \mathrm{ppt}$ (parts per trillion by mass) and an analytical precision of $\pm 10 \%$. Measurements of vanillic acid in Arctic ice core samples from the Siberian Akademii Nauk core are shown as an example application of the method.
\end{abstract}

\section{Introduction}

Biomass burning is an important part of the global carbon cycle and has a major impact on global atmospheric chemistry. Emissions include a wide range of compounds, such as carbon dioxide, carbon monoxide, methane, volatile organic compounds, and aerosols. Emissions of $\mathrm{CO}$ and $\mathrm{CH}_{4}$ affect the global abundance of hydroxyl radicals $(\mathrm{OH})$ and influence the oxidative capacity of the troposphere (Crutzen and Andreae, 1990). Fire also influences climate by changing the albedo of the land surface (Randerson et al., 2006).

Several types of proxy records have been used to reconstruct change in biomass burning over time, but there is little consensus on regional and global trends or on the relationship between biomass burning and global climate. Evidence for historical rates of burning has been obtained from charcoal accumulation in lake sediments and dendrochronologi- cal evidence of fire scars on tree rings (Marlon et al., 2008; Whitlock and Larsen, 2001). Global burning histories have also been inferred from variations in the stable isotopic composition of ice core methane (Ferretti et al., 2005; Sapart et al., 2012).

Past fire events have been detected in Greenland ice from enrichment of ammonium, formate, and oxalate, and the transport of these chemicals to Summit, Greenland, in biomass burning plumes has been documented (Legrand et al., 1992; Dibb et al., 1996; Jaffrezo et al., 1998; Savarino and Legrand, 1998). Acetate and formate also have biogenic sources, which may limit their utility as fire proxies at less remote, continental ice core sites. In a continental Siberian ice core, a fire history was reconstructed from charcoal particles and variations in potassium and nitrate (Eichler et al., 2011). Another ice core chemical used as a biomass burning tracer is levoglucosan, an aerosol-borne anhydrous sugar exclusively produced by burning of cellulose. Levoglucosan is generated from combustion of all types of cellulose-containing plant matter and is therefore not specific to a particular plant type or ecosystem (Simoneit et al., 1999). Levoglucosan has been detected in air over Summit, Greenland, and in both Greenland and Antarctic ice (Kehrwald et al., 2012; Gambaro et al., 2008; Zennaro et al., 2014). There has been some debate about the atmospheric reactivity of levoglucosan and its suitability as a quantitative tracer for aerosol source apportionment (Hoffmann et al., 2010; Hennigan et al., 2010; Slade and Knopf, 2013).

Laboratory and field studies have shown that biomass burning aerosols contain a wide range of aromatic compounds whose chemistry is related to the structure of the precursor lignin material combusted (Simoneit, 2002). These lignin-derived methoxylated phenols, aldehydes, and acids have been used as tracers for the contribution of biomass 


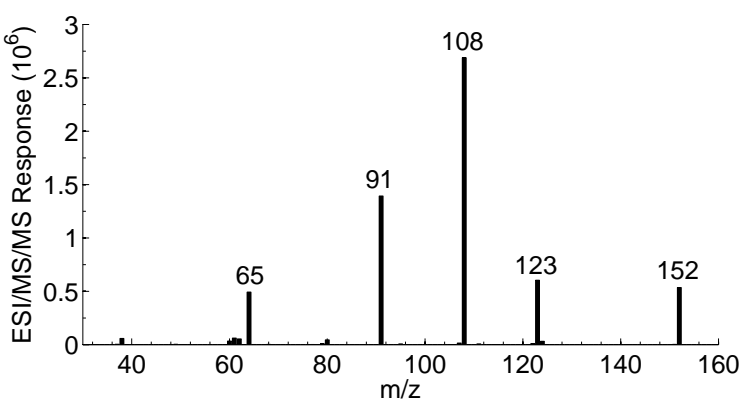

Figure 1. ESI-MS/MS product scan of vanillic acid using $30 \mathrm{eV}$ collision energy.

burning to ambient aerosols on a local or regional basis (Nolte et al., 2001). Such compounds should be incorporated into polar ice cores and may contain information about climate-related variability in biomass burning and about the nature of the combusted material.

In this study we focus on vanillic acid, a product of combustion of conifer lignin. Kawamura et al. (2012) detected vanillic acid in a Kamchatka Peninsula ice core using preconcentration, derivatization, and gas chromatography-mass spectrometry (GC-MS), similar to techniques used for the analysis of biomass burning aerosols (Nolte et al., 2001; Simoneit et al., 2004; Fu et al., 2008). This method involves analysis of relatively large ice core samples $(80-250 \mathrm{~mL})$, with extensive sample handling that requires preconcentration by rotary evaporation, solvent extraction, heated derivatization to form trimethylsilyl derivatives, and dissolution in hexane. Zangrando et al. (2013) reported detection of vanillic acid and other phenolic compounds in Arctic aerosol samples using high-performance liquid chromatography with electrospray ionization and tandem mass spectrometric detection (HPLC-ESI-MS/MS), which avoids the need for chemical derivatization prior to analysis. Our laboratory previously reported the observation of vanillic acid in a Greenland ice core using a continuous flow melter and analysis by ESI-MS/MS (McConnell et al., 2007). That method is capable of high temporal resolution while relying on the selectivity of the ESI-MS/MS to ensure the specificity of the analysis.

Here we report on the development of an analytical method for the rapid analysis of discrete ice core samples employing HPLC-ESI-MS/MS. The performance of the method is illustrated using synthetic aqueous solutions and natural samples from the Siberian Akademii Nauk ice core.

\section{Instrumentation}

This study was carried out using a ThermoFinnigan TSQ Quantum System, consisting of a Surveyor autosampler, a liquid chromatograph (HPLC), and an electrospray ionization-triple quadrupole mass spectrometer (ESIMS/MS). Instrument control and data acquisition used the

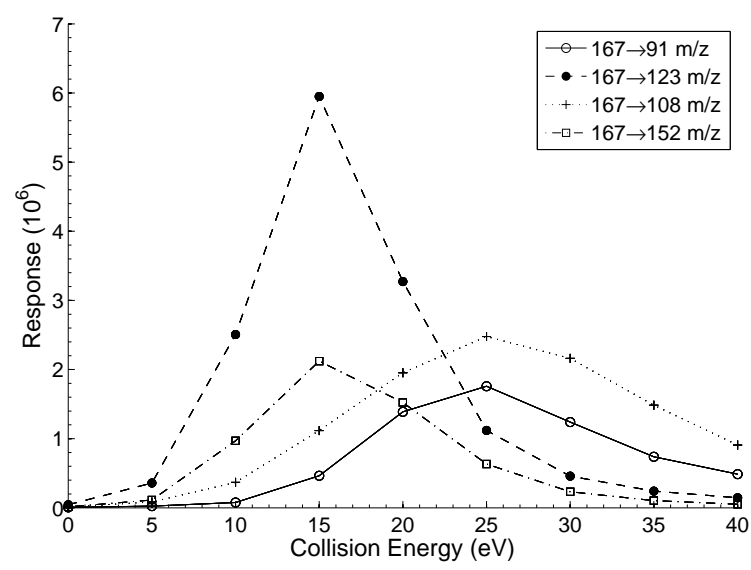

Figure 2. Instrument response to a $1 \mathrm{ppm}$ vanillic acid solution at varying collision energies using the $167 \rightarrow 91 \mathrm{~m} / \mathrm{z}, 167 \rightarrow 123 \mathrm{~m} / \mathrm{z}$, $167 \rightarrow 108 \mathrm{~m} / \mathrm{z}$, and $167 \rightarrow 152 \mathrm{~m} / \mathrm{z}$ mass transitions.

Xcalibur data system (ThermoFinnigan Corp.). The electrospray ion source was operated using the following conditions: $-3 \mathrm{kV}$ spray voltage, $38 \mathrm{psi}$ sheath gas pressure, and $15 \mathrm{psi}$ auxiliary gas pressure. For instrument tuning and signal optimization, high-concentration vanillic acid solutions $(1-10 \mathrm{ppm})$ were introduced directly into the ESI-MS/MS via syringe pump (NE-300, New Era). Vanillic acid was detected using the mass spectrometer in the negative ion mode, with an ion inlet cone temperature of $350{ }^{\circ} \mathrm{C}$.

\section{Method optimization and validation}

\subsection{Collision energy}

MS/MS detection of vanillic acid was optimized using product scans with varying collision energies. Solutions containing $1 \mathrm{ppm}$ vanillic acid in a $75: 25 \%$ water : methanol mixture were delivered directly to the electrospray source using the syringe pump. The vanillic acid $[\mathrm{M}-\mathrm{H}]^{-}(m / z$ 167) was used as the precursor mass, and the collision gas pressure was $1.5 \times 10^{-4} \mathrm{psi}$ of Ar. Figure 1 shows a product scan at a collision energy of $30 \mathrm{eV}$. The major product fragments under these conditions are $\mathrm{C}_{4} \mathrm{H}(\mathrm{O})\left(\mathrm{m} / z\right.$ 65), $\mathrm{C}_{6} \mathrm{H}_{3} \mathrm{O}(\mathrm{m} / z$, 91$)$, $\mathrm{C}_{6} \mathrm{H}_{3}(\mathrm{O}) \mathrm{OH}(\mathrm{m} / z 108), \mathrm{C}_{6} \mathrm{H}_{3}\left(\mathrm{OCH}_{3}\right) \mathrm{OH}(\mathrm{m} / z .123)$, and $\mathrm{C}_{6} \mathrm{H}_{3}(\mathrm{O})(\mathrm{COO}) \mathrm{OH}(m / z$ 152).

Figure 2 shows the fragmentation pattern as a function of collision energy over the range of $0-40 \mathrm{eV}$. Maxima were found at a collision energy of $15 \mathrm{eV}$ for fragments at $m / z 152$ (loss of $\mathrm{CH}_{3}$ ) and $m / z 123$ (loss of $\mathrm{CO}_{2}$ ). Maxima were observed at $25 \mathrm{eV}$ for fragments at $m / z, 108$ (loss of $\mathrm{CH}_{3}$ and $\mathrm{CO}_{2}$ ) and $m / z 91$ (loss of $\mathrm{COOH}$ and $\mathrm{OCH}_{3}$ ). The highest response overall was obtained for the $m / z 123$ fragment at $15 \mathrm{eV}$. However, solvent noise at the $167 \rightarrow 123$ transition was too high to allow detection of vanillic acid in ice core samples. The optimal signal-to-noise ratio was obtained at 

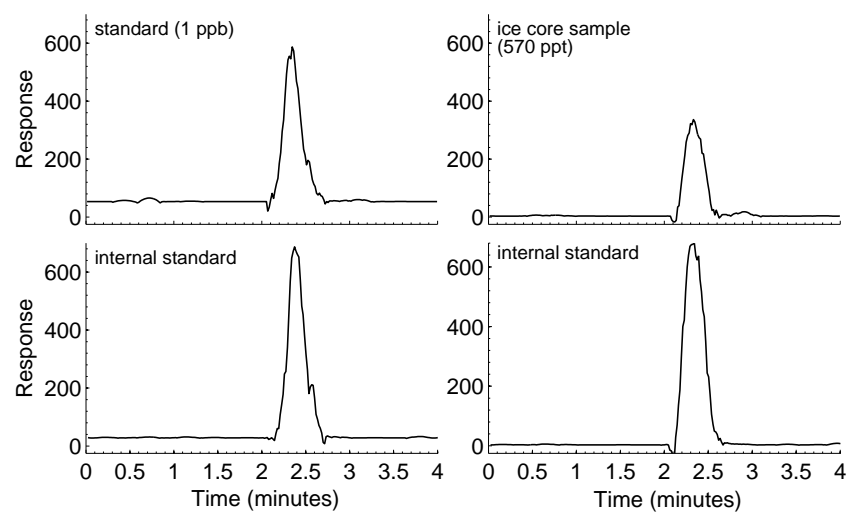

Figure 3. Vanillic acid chromatograms. Left: $1 \mathrm{ppb}$ vanillic acid standard in Milli-Q water $\left({ }^{12} \mathrm{C}, 167 \rightarrow 108 \mathrm{~m} / z\right)$ (upper) with 1 ppbinternal standard $\left({ }^{13} \mathrm{C}\right.$-labeled vanillic acid, $\left.168 \rightarrow 108 \mathrm{~m} / \mathrm{z}\right)$ (lower). Right: Akademii Nauk ice core sample containing $570 \mathrm{ppt}$ vanillic acid (325 $\mathrm{m}$ depth, $\mathrm{AD} 286)\left({ }^{12} \mathrm{C}, 167 \rightarrow 108 \mathrm{~m} / \mathrm{z}\right)$ (upper) with $1 \mathrm{ppb}$ internal standard $\left({ }^{13} \mathrm{C}\right.$-labeled vanillic acid, $168 \rightarrow 108 \mathrm{~m} / \mathrm{z}$ ) (lower).

the $167 \rightarrow 108$ transition at a collision energy of $30 \mathrm{eV}$. These conditions were used in this study.

\subsection{Chromatography}

The autosampler was programmed to inject $100 \mu \mathrm{L}$ of sample onto a reversed-phase Kinetex $2.6 \mu \mathrm{m}$ particle size XB-C18 $100 \mathrm{~A}$ analytical column $(100 \mathrm{~mm} \times 2.2 \mathrm{~mm}$, Phenomenex $)$. The mobile phase was an isocratic solution of $25 \%$ methanol in water, flowing at $200 \mu \mathrm{L} \mathrm{min}^{-1}$. All of the column effluent was directed to the electrospray ionization source. Vanillic acid is eluted from the column with a retention time of $2.5 \mathrm{~min}$ and a peak width at half height of $0.2 \mathrm{~min}$. Chromatograms of standard mixture of a 1 ppb vanillic acid standard $(167 \rightarrow 108)$ and a $1 \mathrm{ppb}{ }^{13} \mathrm{C}$-labeled vanillic acid isotope standard $(168 \rightarrow 108)$ are shown in Fig. 3 (left side).

\subsection{Standardization and limit of detection}

Standards were prepared using vanillic acid (4-hydroxy-3methoxybenzoic acid, $97 \%$ purity, Sigma-Aldrich). The internal standard was ${ }^{13} \mathrm{C}$-labeled vanillic acid (Carboxyl- ${ }^{13} \mathrm{C}$, $99 \%$ purity, Cambridge Isotope Laboratories). Stock solutions of $0.1 \%$ vanillic acid and ${ }^{13} \mathrm{C}$-labeled vanillic acid were prepared monthly in high-performance liquid chromatography (HPLC)-grade methanol (J. T. Baker). Intermediate $1 \mathrm{ppm}$ standards were prepared daily in methanol. Working standards ranging from 0 to $2 \mathrm{ppb}$ were prepared by dilution in ultrapure water (Millipore Milli-Q) directly in $2 \mathrm{~mL}$ Surveyor autosampler vials. The uncertainty in the accuracy of these standards is estimated to be $\pm 4 \%$ based on the stated purity of the reagent grade vanillic acid and the estimated uncertainty in our preparation of working standards. Samples and standards were spiked with ${ }^{13} \mathrm{C}$-labeled vanillic acid
( $2 \mu \mathrm{L}$ of $1 \mathrm{ppm}$ internal standard in $2 \mathrm{~mL}$ ) to generate a $1 \mathrm{ppb}$ internal standard.

Calibration curves were constructed by analyzing vanillic acid standards ranging in concentration from 0 to $3 \mathrm{ppb}$. The calibration curves were based on the ratio of peak areas of the vanillic acid and isotope-labeled vanillic acid signals at their respective mass transitions, $167 \rightarrow 108$ and $168 \rightarrow 108$. Using linear least-squares regression, the slope of the calibration curve was $1.2 \pm 0.025 \mathrm{ppb}^{-1}$ and the intercept was $0.035 \pm 0.047(n=414)$. The detection limit is approximately $0.077 \mathrm{ppb}$, defined as 3 times the standard deviation of vanillic acid measurements in distilled water blanks spiked with the internal standard.

\subsection{Matrix effects}

Because polar ice core samples are complex mixtures of organic and inorganic compounds, it is important to quantify matrix effects that might suppress or enhance analyte response in an ice core sample compared to that in a pure water standard. This was done by comparing the response of the isotope-labeled internal standard in ice core samples to that in pure water. The response to the isotope-labeled standard in ice core samples was identical to that in pure water standards. This clearly demonstrates the absence of significant matrix effects in the Akademii Nauk ice core samples analyzed in this study.

\subsection{Selectivity}

The identity of the vanillic acid peak was confirmed by analyzing a set of ice core samples using anion chromatography with ESI-MS/MS detection. These analyses were carried out on an IonPac AS18-Fast $2 \mu \mathrm{m}$ analytical column with a $40 \mathrm{mM}$ potassium hydroxide eluent at a flow rate of $200 \mu \mathrm{L} \mathrm{min}^{-1}$ and an electrolytically regenerated suppressor. Methanol was added to the eluent stream downstream of the suppressor in order to maintain a stable electrospray ( $70 \mu \mathrm{L} \mathrm{min}^{-1}$, J. T. Baker HPLC-MS grade). As in the HPLC method, the vanillic acid peak in ice core samples was eluted with the same retention time and peak shape as vanillic acid standards or isotope-labeled internal standards $(11.9 \mathrm{~min})$. The fragmentation pattern of the vanillic acid peak in ice core samples was identical to that in vanillic acid standards to within analytical precision (better than $\pm 10 \%$ ). The ratios of the most abundant transitions $(167 \rightarrow 123,167 \rightarrow 108)$ were within $\pm 4 \%$. A set of 47 samples analyzed by HPLC and ion chromatography (IC) gave means of $0.206 \pm 0.135$ and $0.177 \pm 0.127 \mathrm{ppb}( \pm 1 \sigma)$, respectively, with an $r^{2}$ of 0.67 .

\section{Ice core sample analysis}

The ice core samples used to test the analytical method were obtained from the Akademii Nauk ice core (Fritzsche et al., 2005). This ice core was drilled on the Akademii Nauk ice 


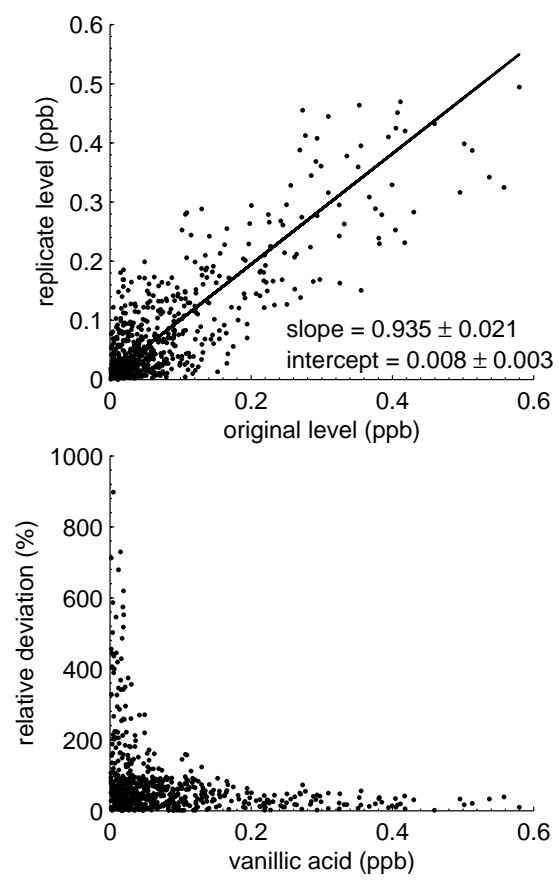

Figure 4. Measured vanillic acid level (ppb) compared to replicate vanillic acid level (ppb) (top). The line is the least-squares fit accounting for both the original and replicate measurements. Vanillic acid level (ppb) compared to the relative standard deviation (\%) (bottom).

cap covering Komsomolets Island in the Eurasian Arctic $\left(80^{\circ} 31^{\prime} \mathrm{N}, 94^{\circ} 49^{\prime} \mathrm{E}\right)$. The site was 800 ma.s.l. with a mean annual temperature of $-15.7^{\circ} \mathrm{C}$. The ice core was drilled to bedrock with a total depth of $723.91 \mathrm{~m}$ (Fritzsche et al., 2002, 2005; Weiler et al., 2005). The ice core samples analyzed for this study covered the time period AD 200-350. This is a provisional timescale (J. McConnell, Desert Research Institute, personal communication). Samples were melted using a continuous melter, and collected in $8 \mathrm{~mL}$ HDPE vials using a peristaltic pump and fraction collector (McConnell et al., 2001).

The procedure used for analysis of ice core samples was as follows: $1 \mathrm{ppb}$ of ${ }^{13} \mathrm{C}$-labeled vanillic acid was added to each ice core sample and standard. Occasional blanks without internal standard were also analyzed. A blank and/or standard was analyzed after every fifth ice core sample. Samples were typically analyzed in batches of 50-70 samples day ${ }^{-1}$ and typically calibration curves were based on all of the standards and blanks analyzed on the same day. An example of a chromatogram from an Akademii Nauk ice core sample is shown in Fig. 3 (right side). The results of duplicate analysis of ice core samples are shown in Fig. 4. The relative standard deviation of duplicates is about $30 \%$ for levels above the detection limit and below $0.600 \mathrm{ppb}(n=167)$.

The vanillic acid observed in 34 Akademii Nauk ice core samples, covering the time period of AD 200-350 is shown

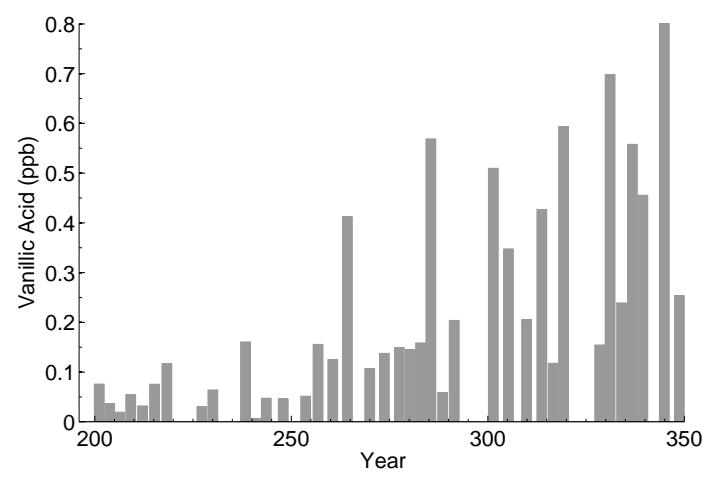

Figure 5. Vanillic acid concentrations in Akademii Nauk ice core samples plotted against ice age for the years AD 200-350.

in Fig. 5. Each sample represents approximately a 1 year average. Vanillic acid concentrations ranged from below the detection limit to $0.698 \mathrm{ppb}$, with an overall mean of $0.226 \pm 0.189 \mathrm{ppb}(1 \sigma)$ and a median of $0.156 \mathrm{ppb}$.

There are few reports of previous ice core measurements of vanillic acid, but the levels reported in the literature are generally similar to those measured here. Kawamura et al. (2012) reported vanillic acid levels ranging from below detection $(0.005 \mathrm{ppb})$ to $0.125 \mathrm{ppb}$ for samples from the Ushkovsky ice core on the Kamchatka Peninsula covering the time period 1690-1997. McConnell et al. (2007) reported vanillic acid levels from 0.001 to $0.350 \mathrm{ppb}$ in ice core samples from west-central Greenland ranging in age from AD 1788 to 2002.

\section{Conclusions}

This study demonstrates the feasibility of analyzing small ice core samples using HPLC-ESI-MS/MS with minimal sample handling. The development of such rapid, low-volume, high-sensitivity analytical methods for analysis of organic compounds is needed in order to fully exploit the paleoenvironmental information stored in the polar ice archive. For organic biomass burning tracers such as vanillic acid, the potential exists to observe variations in the intensity and location of high-latitude biomass burning over long timescales, with the caveat that such signals are influenced by atmospheric transport, chemical reactivity, and deposition.

The detection limit achieved in this study was sufficiently sensitive to detect vanillic acid in a Siberian ice core. The GC-MS method has a lower detection limit $(0.005 \mathrm{ppb}$; Kawamura et al., 2012) and permits simultaneous measurements of a wide range of additional organic compounds derived from biomass burning. However, that technique requires large samples (80-250 mL) and more extensive sample handling. The very small sample size and reduced sample handling requirements of the HPLC-ESI-MS/MS method make it useful for analyzing ice cores at high temporal 
resolution, which is needed in order to study variability in fire magnitude and frequency on decadal timescales. The potential exists to extend the HPLC-ESI-MS/MS technique to measure additional biomass burning products, as has been done for aerosols (Zangrando et al., 2013). This will be the focus of future work.

Acknowledgements. The ice core samples analyzed here were provided by D. Fritzsche and colleagues at the Alfred Wegener Institute Helmholtz Centre for Polar and Marine Research and melted at the Desert Research Institute laboratory of Joseph McConnell. This research was funded by the National Science Foundation (ANT 0839122).

Edited by: C. Barbante

\section{References}

Crutzen, P. J. and Andreae, M. O.: Biomass Burning in the Tropics: Impact on Atmospheric Chemistry and Biogeochemical Cycles, Science, 250, 1669-1678, doi:10.1126/science.250.4988.1669, 1990.

Dibb, J. E., Talbot, R. W., Whitlow, S. I., Shipham, M. C., Winterle, J., McConnell, J., and Bales, R.: Biomass burning signatures in the atmosphere and snow at Summit, Greenland: An event on 5 August 1994, Atmos. Environ., 30, 553-561, doi:10.1016/13522310(95)00328-2, 1996.

Eichler, A., Tinner, W., Brütsch, S., Olivier, S., Papina, T., and Schwikowski, M.: An ice-core based history of Siberian forest fires since AD 1250, Quaternary Sci. Rev., 30, 1027-1034, doi:10.1016/j.quascirev.2011.02.007, 2011.

Ferretti, D. F., Miller, J. B., White, J. W. C., Etheridge, D. M., Lassey, K. R., Lowe, D. C., Meure, C. M. M., Dreier, M. F., Trudinger, C. M., van Ommen, T. D., and Langenfelds, R. L.: Unexpected Changes to the Global Methane Budget over the Past 2000 Years, Science, 309, 1714-1717, doi:10.1126/science.1115193, 2005.

Fritzsche, D., Wilhelms, F., Savatyugin, L. M., Pinglot, J. F., Meyer, H., Hubberten, H.-W., and Miller, H.: A new deep ice core from Akademii Nauk ice cap, Severnaya Zemlya, Eurasian Arctic: first results, Ann. Glaciol., 35, 25-28, doi:10.3189/172756402781816645, 2002.

Fritzsche, D., Schutt, R., Meyer, H., Miller, H., Wilhelms, F., Opel, T., and Savatyugin, L. M.: A 275 year ice core record from Akademii Nauk ice cap, Severnaya Zemlya, Russian Arctic, Ann. Glaciol., 42, 361-366, doi:10.3189/172756405781812862, 2005.

Fu, P., Kawamura, K., and Barrie, L. A.: Photochemical and Other Sources of Organic Compounds in the Canadian High Arctic Aerosol Pollution during Winter-Spring, Environ. Sci. Technol., 43, 286-292, doi:10.1021/es803046q, 2008.

Gambaro, A., Zangrando, R., Gabrielli, P., Barbante, C., and Cescon, P.: Direct Determination of Levoglucosan at the Picogram per Milliliter Level in Antarctic Ice by HighPerformance Liquid Chromatography/Electrospray Ionization Triple Quadrupole Mass Spectrometry, Anal. Chem., 80, 16491655, doi:10.1021/ac701655x, 2008.
Hennigan, C. J., Sullivan, A. P., Collett, J. L., and Robinson, A. L.: Levoglucosan stability in biomass burning particles exposed to hydroxyl radicals, Geophys. Res. Lett., 37, L09806, doi:10.1029/2010GL043088, 2010.

Hoffmann, D., Tilgner, A., Iinuma, Y., and Herrmann, H.: Atmospheric stability of levoglucosan: a detailed laboratory and modeling study., Environ. Sci. Technol., 44, 694-699, doi:10.1021/es902476f, 2010.

Jaffrezo, J. L., Davidson, C. I., Kuhns, H. D., Bergin, M. H., Hillamo, R., Maenhaut, W., Kahl, J. W., and Harris, J. M.: Biomass burning signatures in the atmosphere of central Greenland, J. Geophys. Res.-Atmos., 103, 31067-31078, doi:10.1029/98JD02241, 1998.

Kawamura, K., Izawa, Y., Mochida, M., and Shiraiwa, T.: Ice core records of biomass burning tracers (levoglucosan and dehydroabietic, vanillic and p-hydroxybenzoic acids) and total organic carbon for past 300 years in the Kamchatka Peninsula, Northeast Asia, Geochim. Cosmochim. Ac., 99, 317-329, doi:10.1016/j.gca.2012.08.006, 2012.

Kehrwald, N., Zangrando, R., Gabrielli, P., Jaffrezo, J.-L., Boutron, C., Barbante, C., and Gambaro, A.: Levoglucosan as a specific marker of fire events in Greenland snow, Tellus B, 64, 18169, doi:10.3402/tellusb.v64i0.18196, 2012.

Legrand, M., De Angelis, M., Staffelbach, T., Neftel, A., and Stauffer, B.: Large perturbations of ammonium and organic acids content in the summit-Greenland Ice Core. Fingerprint from forest fires?, Geophys. Res. Lett., 19, 473-475, doi:10.1029/91GL03121, 1992.

Marlon, J. R., Bartlein, P. J., Carcaillet, C., Gavin, D. G., Harrison, S. P., Higuera, P. E., Joos, F., Power, M. J., and Prentice, I. C.: Climate and human influences on global biomass burning over the past two millennia, Nat. Geosci., 1, 697-702, doi:10.1038/ngeo313, 2008

McConnell, J. R., Lamorey, G. W., Lambert, S. W., and Taylor, K. C.: Continuous Ice-Core Chemical Analyses Using Inductively Coupled Plasma Mass Spectrometry, Environ. Sci. Technol., 36, 7-11, doi:10.1021/es011088z, 2001.

McConnell, J. R., Edwards, R., Kok, G. L., Flanner, M. G., Zender, C. S., Saltzman, E. S., Banta, J. R., Pasteris, D. R., Carter, M. M., and Kahl, J. D. W.: 20th-Century Industrial Black Carbon Emissions Altered Arctic Climate Forcing, Science, 317, 1381-1384, doi:10.1126/science.1144856, 2007.

Nolte, C. G., Schauer, J. J., Cass, G. R., and Simoneit, B. R. T.: Highly Polar Organic Compounds Present in Wood Smoke and in the Ambient Atmosphere, Environ. Sci. Technol., 35, 1912 1919, doi:10.1021/es001420r, 2001.

Randerson, J. T., Liu, H., Flanner, M. G., Chambers, S. D., Jin, Y., Hess, P. G., Pfister, G., Mack, M. C., Treseder, K. K., Welp, L. R., Chapin, F. S., Harden, J. W., Goulden, M. L., Lyons, E., Neff, J. C., Schuur, E. A. G., and Zender, C. S.: The Impact of Boreal Forest Fire on Climate Warming, Science, 314, 1130-1132, doi:10.1126/science.1132075, 2006.

Sapart, C. J., Monteil, G., Prokopiou, M., van de Wal, R. S. W., Kaplan, J. O., Sperlich, P., Krumhardt, K. M., van der Veen, C., Houweling, S., Krol, M. C., Blunier, T., Sowers, T., Martinerie, P., Witrant, E., Dahl-Jensen, D., and Rockmann, T.: Natural and anthropogenic variations in methane sources during the past two millennia, Nature, 490, 85-88, doi:10.1038/nature11461, 2012. 
Savarino, J. and Legrand, M.: High northern latitude forest fires and vegetation emissions over the last millennium inferred from the chemistry of a central Greenland ice core, J. Geophys. Res.Atmos., 103, 8267-8279, doi:10.1029/97JD03748, 1998.

Simoneit, B., Schauer, J., Nolte, C., Oros, D., Elias, V., Fraser, M., Rogge, W., and Cass, G.: Levoglucosan, a tracer for cellulose in biomass burning and atmospheric particles, Atmos. Environ., 33, 173-182, doi:10.1016/S1352-2310(98)00145-9, 1999.

Simoneit, B. R. T.: Biomass burning - a review of organic tracers for smoke from incomplete combustion, Appl. Geochem., 17, 129162, doi:10.1016/S0883-2927(01)00061-0, 2002.

Simoneit, B. R. T., Elias, V. O., Kobayashi, M., Kawamura, K., Rushdi, A. I., Medeiros, P. M., Rogge, W. F., and Didyk, B. M.: Sugars Dominant: Water-Soluble Organic Compounds in Soils and Characterization as Tracers in Atmospheric Particulate Matter, Environ. Sci. Technol., 38, 59395949, doi:10.1021/es0403099, 2004.

Slade, J. H. and Knopf, D. A.: Heterogeneous $\mathrm{OH}$ oxidation of biomass burning organic aerosol surrogate compounds: assessment of volatilisation products and the role of $\mathrm{OH}$ concentration on the reactive uptake kinetics, Phys. Chem. Chem. Phys., 15, 5898-915, doi:10.1039/C3CP44695F, 2013.
Weiler, K., Fischer, H., Fritzsche, D., Ruth, U., Wilhelms, F., and Miller, H.: Glaciochemical reconnaissance of a new ice core from Severnaya Zemlya, J. Glaciol., 51, 64-74, doi:10.3189/172756505781829629, 2005.

Whitlock, C. and Larsen, C.: Charcoal as a Fire Proxy, Tracking Environmental Change Using Lake Sediments, edited by Smol, J., Birks, H., Last, W., Bradley, R., and Alverson, K., vol. 3 of Developments in Paleoenvironmental Research, 75-97, Springer, Netherlands, doi:10.1007/0-306-47668-1_5, 2001.

Zangrando, R., Barbaro, E., Zennaro, P., Rossi, S., Kehrwald, N. M., Gabrieli, J., Barbante, C., and Gambaro, A.: Molecular Markers of Biomass Burning in Arctic Aerosols, Environ. Sci. Technol., 47, 8565-8574, doi:10.1021/es400125r, 2013.

Zennaro, P., Kehrwald, N., McConnell, J. R., Schüpbach, S., Maselli, O. J., Marlon, J., Vallelonga, P., Leuenberger, D., Zangrando, R., Spolaor, A., Borrotti, M., Barbaro, E., Gambaro, A., and Barbante, C.: Fire in ice: two millennia of boreal forest fire history from the Greenland NEEM ice core, Clim. Past, 10, 1905-1924, doi:10.5194/cp-10-1905-2014, 2014. 